\title{
Ranking All DEA-Efficient DMUs Based on Cross Efficiency and Analytic Hierarchy Process Methods
}

\author{
Dariush Akbarian \\ Department of Mathematics, Islamic Azad University, Arak Branch, Arak, Iran \\ Correspondence should be addressed to Dariush Akbarian; d_akbarian@yahoo.com
}

Received 15 August 2014; Accepted 20 December 2014

Academic Editor: Farhad Hosseinzadeh Lotfi

Copyright (c) 2015 Dariush Akbarian. This is an open access article distributed under the Creative Commons Attribution License, which permits unrestricted use, distribution, and reproduction in any medium, provided the original work is properly cited.

\begin{abstract}
The aim of this paper is to present an original approach for ranking of DEA-efficient DMUs based on the cross efficiency and analytic hierarchy process (AHP) methods. The approach includes two basic stages. In the first stage using DEA models the cross efficiency value of each DEA-efficiency DMU is specified. In the second stage, the pairwise comparison matrix generated in the first stage is utilized to rank scale of the units via the one-step process of AHP. The advantage of this proposed method is its capability of ranking extreme and nonextreme DEA-efficient DMUs. The numerical examples are presented in this paper and we compare our approach with some other approaches.
\end{abstract}

\section{Introduction}

Data envelopment analysis (DEA) is a tool for evaluation and measuring of the efficiency of a set of decision making units (DMUs) that consume multiple inputs and produce multiple outputs, first introduced by Charnes, Cooper, and Rhodes (CCR) [1] and extended by Banker, Charnes, and Cooper (BCC) [2]. DEA is used to establish a best practice group from among a set of observed units and to identify the units that are inefficient when compared to the best practice group [36]. One important issue in DEA which has been studied by many DEA researchers is to discriminate between efficient DMUs. Several authors have proposed methods for ranking the best performers ([7-14] among others). Perhaps the most widely known and applied ranking method is the superefficiency DEA model. Developed by Andersen and Petersen [13], the main idea of this approach is to evaluate DMU after this performer itself is excluded from the reference set. The problem with super-efficiency DEA is that under certain conditions infeasibility occurs which limits the applicability of the technique (for details see [15]). Wu [4] utilized the concept of fuzzy for ranking of DMUs in the traditional DEA models. For this purpose, firstly the DMUs are evaluated by the CCR and the cross efficiency models. Secondly, a fuzzy preference relation is established. Finally, a priority vector of the preference is constructed and is used for ranking DMUs. Jahanshahloo et al. [8] proposed a ranking system based on changing reference set. In the proposed ranking system, the evaluation for efficient DMUs is dependent on the efficiency changes of all inefficient units due to its absence in the reference set while the estimate for inefficient DMUs depends on the influence of the exclusion of each efficient unit from the reference set. One popular method to rank multiple alternatives with respect to multiple criteria is analytical hierarchy process (AHP) method developed by Saaty [16]. The analytic hierarchy process is a multicriteria decision making technique and was used for complete ranking of DMUs by Sinuany-Stern et al. [17] and Jablonsky [18, 19] and references cited therein. Sinuany-Stern et al. [17] presented an AHP/DEA methodology for ranking DMUs, which integrates DEA and the AHP. In this AHP/DEA methodology, DEA was first run for each pair of DMUs separately to create a pairwise comparison matrix, which was then solved using the eigenvector method to produce a full ranking for all DMUs, efficient and inefficient. Their method has some problems, such as illogic comparing of two DMUs in a DEA model (see [20] for details). Alirezaee and Sani [20] extended Sinuany-Stern's approach and proposed a new two-stage AHP/DEA methodology for ranking DMUs that removes these problems. They used together with the efficiency of 
units the influence rate of each unit to the other units in order to determine the elements of pairwise comparison matrix. Jablonsky [18] used an AHP model with interval pairwise comparisons for the evaluation and classification of efficient units and compares the results with super-efficiency DEA scores. In [19], Jablonsky presented an original procedure for ranking of DMUs in DEA models based on combination of AHP and DEA principles. He/she considered the DMUs as alternatives and the ratios of output/input as criteria. An extensive review of ranking models in DEA is given in Adler et al. [12]. The aim of this paper is to propose a method for ranking extreme and nonextreme efficient DMUs using cross efficiency and AHP methods. Our approach includes two stages. In the first step using DEA models the cross efficiency value of each DEA-efficiency DMU is specified. In the second stage, the pairwise comparison matrix generated in the first step is utilized to rank scale of the units via the AHP. This paper is organized as follows. Section 2 presents some basic DEA models and reviews some ranking method. In Section 3 we briefly review the AHP. Section 4 gives a brief introduction to the cross efficiency evaluation. The new ranking method for DEA-efficient DMUs is developed in Section 5. Numerical examples are examined in Section 6. The paper is concluded in Section 7.

\section{Data Envelopment Analysis Models}

Consider a set of $n$ DMUs which is associated with $m$ inputs and $s$ outputs. Particularly, $\mathrm{DMU}_{j}(j \in J=1, \ldots, n)$ consumes amount $x_{i j}$ of input $i$ and produces amount $y_{r j}$ of output $r$. Let $X_{j}=\left(x_{1 j}, \ldots, x_{m j}\right)$ in which $X_{j} \geq 0$ and $X_{j} \neq 0$ and $Y_{j}=\left(y_{1 j}, \ldots, y_{r j}\right)$ in which $Y_{j} \geq 0$ and $Y_{j} \neq 0$. The production possibility set (PPS) of CCR model is defined as follows:

$$
T_{\mathrm{CCR}}=\left\{(X, Y) \mid X \geqq \sum_{j=1}^{n} \lambda_{j} X_{j}, Y \leqq \sum_{j=1}^{n} \lambda_{j} Y_{j}, \lambda_{j} \geqslant 0, j \in J\right\}
$$

and similarly the production possibility set of BCC model is defined as follows:

$$
\begin{gathered}
T_{\mathrm{BCC}}=\left\{(X, Y) \mid X \geqq \sum_{j=1}^{n} \lambda_{j} X_{j}, Y \leqq \sum_{j=1}^{n} \lambda_{j} Y_{j},\right. \\
\left.\sum_{j=1}^{n} \lambda_{j}=1, \lambda_{j} \geqslant 0, j \in J\right\} .
\end{gathered}
$$

The input-oriented BCC and input-oriented CCR models, corresponding to $\mathrm{DMU}_{p}, p \in J$, are given by (3) and (4), respectively:

$$
\begin{array}{ll}
\min & \theta-\epsilon\left(\sum_{i=1}^{m} s_{i}^{-}+\sum_{r=1}^{s} s_{r}^{+}\right) \\
\text {s.t. } & \sum_{j \in J} \lambda_{j} y_{r j}-s_{r}^{+}=y_{r p}, \quad r=1, \ldots, s \\
& \sum_{j \in J} \lambda_{j} x_{i j}+s_{i}^{-}=\theta x_{i p}, \quad i=1, \ldots, m
\end{array}
$$

$$
\begin{array}{ll}
\sum_{j \in J} \lambda_{j}=1 & \\
\lambda_{j} \geq 0, & j \in J \\
s_{i}^{-} \geq 0, & i=1, \ldots, m \\
s_{r}^{+} \geq 0, & r=1, \ldots, s \\
\theta \quad \text { free } &
\end{array}
$$

$$
\begin{array}{ll}
\min & \theta-\epsilon\left(\sum_{i=1}^{m} t_{i}^{-}+\sum_{r=1}^{s} t_{r}^{+}\right) \\
\text {s.t. } & \sum_{j \in J} \lambda_{j} x_{i j}+t_{i}^{-}=\theta x_{i p}, \quad i=1, \ldots, m \\
& \sum_{j \in J} \lambda_{j} y_{r j}-t_{r}^{+}=y_{r p}, \quad r=1, \ldots, s \\
& \lambda_{j} \geq 0, \quad j \in J \\
& t_{i}^{-} \geq 0, \quad i=1, \ldots, m \\
& t_{r}^{+} \geq 0, \quad r=1, \ldots, s \\
& \theta \quad \text { free },
\end{array}
$$

where $\epsilon$ is non-Archimedean small and positive number and $s_{i}^{-}, s_{r}^{+}, t_{i}^{-}$, and $t_{r}^{+}, i=1, \ldots, m, r=1, \ldots, s$, are called slack variables belonging to $\mathbb{R}^{\geq 0}$. Note that $s_{i}^{-}$and $t_{i}^{-}$represent input excesses; also $s_{r}^{+}$and $t_{r}^{+}$represent output shortfalls. Also $\theta$ and $\lambda_{j}, j \in J$, are real numbers and $\lambda_{j} \in \mathbb{R}^{\geq 0}$. Models (3) and (4) are called envelopment forms (with nonArchimedean number).

$\mathrm{DMU}_{p}$ is said to be strong efficient (CCR-efficient) if and only if $\theta^{*}=1$ and $\mathbf{t}^{+*}=\mathbf{0}$ and $\mathbf{t}^{-*}=\mathbf{0}$. Where the superscript $\left({ }^{*}\right)$ indicates optimality. In similar manner the BCC-efficient DMUs can be defined.

The dual of model (4) (without $\epsilon$, i.e., $\epsilon=0$ ), which is called multiplier form (corresponding to $\mathrm{DMU}_{k}$ ), is as follows:

$$
\begin{array}{ll}
\max & \theta_{k k}=\sum_{r=1}^{s} u_{r k} y_{r k} \\
\text { s.t. } & \sum_{r=1}^{s} u_{r k} y_{r j}-\sum_{i=1}^{m} v_{i k} x_{i j} \leq 0, \quad j=1, \ldots, n \\
& \sum_{i=1}^{m} v_{i k} x_{i k}=1, \\
& u_{r k} \geq 0, \quad r=1, \ldots, s \\
& v_{i k} \geq 0, \quad i=1, \ldots, m .
\end{array}
$$

The AP model is as follows [13]:

$$
\begin{array}{ll}
\min & \theta \\
\text { s.t. } & \sum \lambda_{j \in J-\{p\}} y_{r j} \geq y_{r p}, \quad r=1, \ldots, s \\
& \sum_{j \in J-\{p\}} \lambda_{j} x_{i j} \leq \theta x_{i p}, \quad i=1, \ldots, m \\
& \lambda_{j} \geq 0, \quad j \in J-\{p\} \\
& \theta \quad \text { free. }
\end{array}
$$


Jahanshahloo's method corresponding inefficient $\mathrm{DMU}_{a}$ is as follows [8]:

$$
\begin{array}{ll}
\min & \theta-\epsilon\left(\sum_{i=1}^{m} s_{i}^{-}+\sum_{r=1}^{s} s_{r}^{+}\right) \\
\text {s.t. } & -\sum_{j \in J-\{b\}} \lambda_{j} x_{i j}+\theta x_{i a}-s_{i}^{-}=0, \quad i=1, \ldots, m \\
& \sum_{j \in J-\{b\}} \lambda_{j} y_{r j}-s_{r}^{+}=y_{r a}, \quad r=1, \ldots, s \\
& \lambda_{j} \geq 0, \quad j \in J-\{b\} \\
& s_{i}^{-} \geq 0, \quad i=1, \ldots, m \\
& s_{r}^{+} \geq 0, \quad r=1, \ldots, s \\
& \theta, \quad \text { free. }
\end{array}
$$

The efficiency of strong efficiency $\mathrm{DMU}_{b}$ will be denoted by $\Omega$ and will be given by

$$
\Omega_{b}=\frac{\sum_{a \in J_{n}} \partial_{a, b}}{\widetilde{n}}
$$

in which $J_{n}$ is the set of nonstrong efficiency DMUs and $\widetilde{n}$ is the number of nonstrong efficiency DMUs.

Jahanshahloo et al. [21] used $l_{1}$-norm in order to rank the extremely efficient DMUs in DEA models with constant and variable returns to scale, and the proposed method can remove the difficulties arising from AP and MAJ [11] models. Their proposed model is as follows:

$$
\begin{array}{ll}
\min & \quad \Gamma_{p}^{c}(X, Y)=\sum_{i=1}^{m}\left|x_{i}-x_{i p}\right|+\sum_{r=1}^{s}\left|y_{r}-y_{r p}\right| \\
\text { s.t. } & \sum_{j \in J-\{p\}} \lambda_{j} x_{i j} \leq x_{i}, \quad i=1, \ldots, m \\
& \sum_{j \in J-\{p\}} \lambda_{j} y_{r j} \geq y_{r}, \quad r=1, \ldots, s \\
& x_{i} \geq 0, \quad i=1, \ldots, m \\
& y_{r} \geq 0, \quad r=1, \ldots, s \\
& \lambda_{j}^{p} \geq 0, \quad j \in J-\{p\} .
\end{array}
$$

As mentioned earlier, Sinuany-Stern's approach [17] is a two-stage model for fully ranking model. In the first stage Sinuany-Stern run the following CCR model for each pair of DMUs $A$ and $B$ :

$$
\begin{array}{ll}
\max & E_{A A}=\sum_{r=1}^{s} u_{r} y_{r A} \\
\text { s.t. } & \sum_{r=1}^{s} u_{r k} y_{r B}-\sum_{i=1}^{m} v_{i} x_{i B} \leq 0, \quad j=1, \ldots, n \\
& \sum_{i=1}^{m} v_{i} x_{i A}=1,
\end{array}
$$

$$
\begin{aligned}
& \sum_{r=1}^{s} u_{r} y_{r A} \leq 1, \\
& u_{r} \geq 0, \quad r=1, \ldots, s \\
& v_{i} \geq 0, \quad i=1, \ldots, m .
\end{aligned}
$$

$E_{A A}$ is the efficiency score of unit $A$. The cross efficiency of DMU $A$ is as follows:

$$
E_{B A}=\frac{\sum_{r=1}^{s} u_{r}^{*} y_{r B}}{\sum_{i=1}^{m} v_{i}^{*} x_{i B}}
$$

in which $u_{r}^{*}$ and $v_{i}^{*}$ are the optimal weights of model (10). In the similar manner $E_{A B}$ and $E_{A A}$ can be computed. The pairwise comparison matrix $\mathbf{A}=\left[a_{i j}\right](i, j=1, \ldots, n)$ is constructed as follows:

$$
a_{i j}=\frac{E_{i i}+E_{i j}}{E_{j j}+E_{j i}}, \quad a_{i i}=1 .
$$

In the second stage using a one-step process (Step 3 in Section 3), the vector weights of the pairwise comparison matrix $\mathbf{A}$ are computed. Based on these weights, the efficient and inefficient DMUs are ranked.

Alirezaee and Sani [20] proposed a two-stage AHP/DEA methodology for ranking DMUs. In the first stage they create the pairwise comparison matrix as follows.

First, using CCR model (4) the relative efficiency of each DMU is determined. Then, each DMU is evaluated by the following model:

$$
\begin{array}{ll}
\min & \theta \\
\text { s.t. } & \sum_{j=1, j \neq k}^{n} \lambda_{j} y_{r j} \geq y_{r p}, \quad r=1, \ldots, s \\
& \sum_{j=1, j \neq k}^{n} \lambda_{j} x_{i j} \leq \theta x_{i p}, \quad i=1, \ldots, m \\
& \lambda_{j} \geq 0, \quad j=1, \ldots, n, \quad j \neq k \\
& \theta \quad \text { free. }
\end{array}
$$

This model measures efficiency DMU $\mathrm{D}_{p}$ after excluding $\mathrm{DMU}_{k}$ from PPS. The pairwise comparison matrix $\mathbf{A}$ is constructed as follows:

$$
\mathbf{A}=\left[a_{i j}\right], \quad a_{i j}=\frac{T E^{i}+\left\{T E_{i}^{j}-T E^{j}\right\}}{T E^{j}+\left\{T E_{j}^{i}-T E^{i}\right\}}, \quad i, j=1, \ldots, n,
$$

in which $T E^{i}$ and $T E_{j}^{i}$ are the objective function of (4) and (13) at optimality, respectively.

In the second stage, similar to AHP/DEA method, using a one-step process of AHP, the DMUs are ranked. In this paper we rank DMUs in the CCR model; in a similar way one can also rank DMUs in the BCC model. 
TABLE 1: Random index.

\begin{tabular}{lccccccccc}
\hline Matrix order & 1 & 2 & 3 & 4 & 5 & 6 & 7 & 8 & 9 \\
\hline RI & 0.00 & 0.00 & 0.58 & 0.9 & 1.12 & 1.24 & 1.32 & 1.41 & 1.45 \\
\hline
\end{tabular}

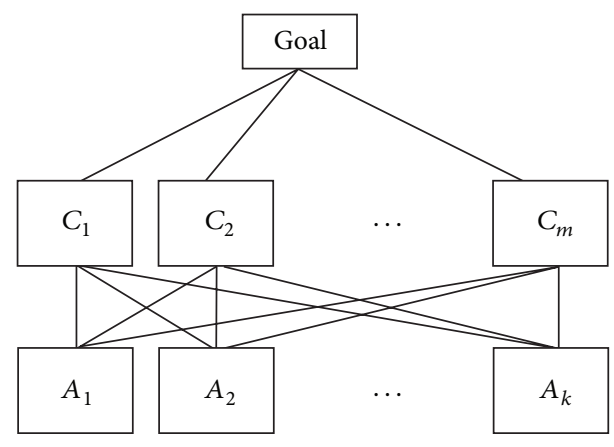

FIGURE 1: Three-level hierarchy.

\section{Analytical Hierarchy Process (AHP)}

AHP is a powerful tool for analysis of complex decision problems. AHP is employed for ranking a set of alternatives or for the selection of the best in a set of alternatives with respect to multiple criteria. In this section a brief discussion of AHP is provided. For more details see Saaty [16].

Application of AHP to a decision problem involves four steps $[23,24]$.

Step 1 (structuring of the decision problem into a hierarchical model). The first step is to decompose a decision problem into elements. In its simplest form (Figure 1), this structure comprises a goal at the topmost level, criteria (and subcriteria) at the intermediate levels, while the lowest level contains a set of the alternatives. A simple AHP model (Figure 1) has three levels (goal, criteria, and alternatives).

Step 2 (making pairwise comparisons and obtaining the judgment matrix). In this step, the elements of a particular level are compared with respect to a specific element in the immediate upper level. The more important (or more attractive) element receives higher rating (between 1 and 9) than another one that has the less important element [16]. The comparisons are used to form a matrix of pairwise comparisons called the judgment (pairwise comparison) matrix A. Each entry $a_{i j}$ of the judgment matrix satisfied the three rules: $a_{i j}>0 ; a_{i j}=1 / a_{j i}$; and $a_{i i}=1$ for all $i, j$. In fact, the number $a_{i j}$ shows the relative importance of alternative $A_{i}$ in comparison with alternative $A_{i}$ with respect to criterion $C_{j}$ or the relative importance of criteria $C_{i}$ in comparison with criterion $C_{j}$ with respect to goal. If $a_{i j}=a_{i k} \cdot a_{k j}$, for all the entries of the matrix, then the matrix is said to be consistent. If the property does not hold for all the entries, the level of inconsistency can be captured by a measure called consistency ratio [16] (see next step).

Step 3 (local weights and consistency of comparisons). In this step, local weights of the elements are calculated from the judgment matrices using the eigenvector method (EVM). The normalized eigenvector corresponding to the principal eigenvalue of the judgment matrix provides the weights of the corresponding elements. Though EVM is followed widely in traditional AHP computations, other methods are also suggested for calculating weights, including the logarithmic least-square technique (LLST) [25, 26], goal programming [27], and recently DEAHP method [15, 16, 20, 22, 24-33]. When EVM is used, consistency ratio (CR) can be computed. The consistency index (CI) is calculated as follows:

$$
\mathrm{CI}=\frac{\lambda_{\max }-1}{n-1}
$$

in which $n$ is the number of criteria and $\lambda_{\max }$ is the maximum eigenvalue of the judgment matrix. Then, the consistency ratio (CR) is calculated as the ratio of consistency index and random index $(\mathrm{RI})$; that is,

$$
\mathrm{CR}=\frac{\mathrm{CI}}{\mathrm{RI}}
$$

Random index is the consistency index of a randomly generated reciprocal matrix from the scales 1 to 9 . Table 1 shows the value of RI sorted by the order of matrix. For a consistent matrix $\mathrm{CR}=0$ and $\lambda_{\max }=n$. A value of $\mathrm{CR}$ less than 0.1 is considered acceptable because human judgments need not be always consistent, and there may be inconsistencies introduced because of the nature of scale used. In the inconsistency case, $\lambda_{\max } \geq n$. If CR for a matrix is more than 0.1 , judgments should be elicited once again from the DM till he\she gives more consistent judgments.

Remark 1. If the pairwise comparisons matrix is as follows:

$$
\mathbf{A}=\left[\begin{array}{cccc}
\frac{w_{1}}{w_{1}} & \frac{w_{1}}{w_{2}} & \cdots & \frac{w_{1}}{w_{n}} \\
\frac{w_{2}}{w_{1}} & \frac{w_{2}}{w_{2}} & \cdots & \frac{w_{2}}{w_{n}} \\
\vdots & \vdots & \vdots & \vdots \\
\frac{\dot{w}_{n}}{w_{1}} & \frac{\dot{w}_{n}}{w_{2}} & \cdots & \frac{\dot{w}_{n}}{w_{n}}
\end{array}\right]
$$

then any weight derivation method, when applied to the above matrix $\mathbf{A}$, should generate the true weights $w_{1}, w_{2}, \ldots, w_{n}$.

Step 4 (aggregation of weights across various levels to obtain the final weights of alternatives). In order to obtain final weights of the decision alternatives (elements at the lowest level), the local weights of elements of different levels are aggregated. For example, the final weight of alternative $A_{p}$ 
is computed using the following hierarchical (arithmetic) aggregation rule in traditional AHP:

$$
\begin{aligned}
& \text { Final weight of } A_{p} \\
& \qquad \begin{array}{l}
\sum_{j}\left[\left(\text { Local weight of } A_{p} \text { with respect to } C_{j}\right)\right. \\
\left.\quad \times\left(\text { Local weight of criterion } C_{j}\right)\right] .
\end{array}
\end{aligned}
$$

By definition, the weights of alternatives and importance of criteria are normalized. The final weights represent the rating of the alternatives in achieving the goal of the problem.

\section{Cross Efficiency Evaluation}

The cross efficiency evaluation was first proposed by Sexton et al. [30] and was later investigated by Doyle and Green [34, 35]. It is often calculated as a two-stage process. In the first stage, the optimal weights of inputs and outputs are calculated for each DMU using the classical DEA formulation, for example, CCR model (5). Let $u_{r k}^{*}(r=1,2, \ldots, s)$ and $v_{i k}^{*}(i=1, \ldots, m)$ be the optimal solution to the LP (5). Then, $\theta_{k k}^{*}=\sum_{r=1}^{s} u_{r k}^{*} y_{r k}$ is referred to as the optimistic efficiency or CCR efficiency of $\mathrm{DMU}_{k}$, which reflects the self-evaluation of $\mathrm{DMU}_{k}$, whereas $\theta_{j k}$ is referred to as a cross efficiency value of $\mathrm{DMU}_{j}$, which reflects the peer-evaluation of $\mathrm{DMU}_{k}$ to $\mathrm{DMU}_{j}(j=1, \ldots, n$; $j \neq k$ ). Consider

$$
\theta_{j k}=\frac{\sum_{r=1}^{s} u_{r k}^{*} y_{r j}}{\sum_{i=1}^{m} v_{i k}^{*} x_{i j}}, \quad k=1, \ldots, n, j=1, \ldots, n .
$$

Therefore, each DMU will have multiple different efficiency scores, whose average reflects the overall performance of the DMU. Based on average cross efficiencies, DMUs can be compared and ranked.

In general, the optimal weights obtained using classical DEA in the first stage are multiple solutions. Therefore, the values $\theta_{k j}^{*}$ will change depending on these values in the second stage. In the second stage, these drawbacks are reduced and a suitable set of weights preserving the efficiency values obtained by DEA is selected for each DMU. To reduce this undesirable case, there are some model suggestions for preserving the self-efficiency scores, $\theta_{k k}^{*}$, obtained for each DMU. Sexton et al. [30] suggested introducing a secondary goal to optimize the input and output weights while keeping the CCR efficiency unchanged. According to Sexton et al. [30], the secondary goals could be, for example, either aggressive or benevolent. In the aggressive context, $\mathrm{DMU}_{k}$ chooses the optimal solutions such that it maximizes selfefficiency and at a secondary level minimizes the other DMUs cross efficiency levels. The benevolent secondary objective would be to maximize all DMUs cross efficiency rankings. The most widely used secondary goals were suggested by Doyle and Green [34]. Wang and Chin [31] propose several new data envelopment analysis (DEA) models for cross efficiency evaluation by introducing a virtual ideal DMU (IDMU) and a virtual anti-ideal DMU (ADMU). These new DEA models determine the input and output weights by minimizing the distance of a DMU from IDMU or maximizing the distance between the DMU and ADMU or both of them simultaneously, without the use of the input and output information of the other DMUs as a secondary goal. Örkcü and Bal [33] presented goal programming models that could be used in the second stage of the cross evaluation. See also [31] for new alternative models for DEA cross efficiency evaluation. In this paper we present another secondary goal to the choice of weights among the alternative optimal solutions. For this aim, we first find the alternative optimal solutions corresponding to all extreme DEA-efficient DMUs using the algorithm proposed by Jahanshahloo et al. [36]. Then, the any nonnegative convex linear combination of these alternative optimal solutions can be considered as the chosen weights corresponding to $\mathrm{DMU}_{k}$ (in this paper we consider the arithmetic mean of the alternative optimal solutions). The advantage of our approach is that in second stage it yields the positive weights (see Remark 2). We emphasize that one may choose another secondary goal to determine the input and output weights.

Remark 2. Any convex linear combination of optimal solutions of the following LP is optimal too:

$$
\begin{array}{ll}
\max & c x \\
\text { s.t. } & \mathrm{A} x \leq b \\
& x \geq 0
\end{array}
$$

in which $\mathbf{A}$ is the $m \times n$ matrix and $x, c$, and $b$ are the $n \times 1$ and $m \times 1$ vectors, respectively.

\section{Proposed Method}

In this section we combine the cross efficiency method with AHP technique and provide a two-stage method for ranking all DEA-efficient DMUs using cross efficient approach and AHP technique. In the first stage, we obtain the CCRefficient DMUs and the optimal solutions of the CCR model (5) corresponding to them. Note that model (5) may have the multiple solutions. In this case, we apply the proposed algorithm in [36] as secondary goal. Suppose $\left(u_{1 k}^{*}, u_{2 k}^{*}, \ldots, u_{s k}^{*}, v_{1 k}^{*}, v_{2 k}^{*}, \ldots, v_{m k}^{*}\right)$ are the optimal solutions (weights) of LP (5) corresponding to $\mathrm{DMU}_{k}$. The efficiency score of CCR-efficient $\mathrm{DMU}_{j}$ using the weights of $\mathrm{DMU}_{k}$ is as follows:

$$
\theta_{j k}=\frac{\sum_{r=1}^{s} u_{r k}^{*} y_{r j}}{\sum_{i=1}^{m} v_{i k}^{*} x_{i j}}, \quad k=1, \ldots, n, j=1, \ldots, n .
$$

Also, $\theta_{j k}$ is referred to as a cross efficiency value of $\mathrm{DMU}_{j}$, which reflects the peer-evaluation of $\mathrm{DMU}_{k}$ to $\mathrm{DMU}_{j}(j=$ $1, \ldots, n ; j \neq k)$. Furthermore, if the input-output weights of the LP (5) are not unique, the arithmetic mean of the alternative optimal solutions corresponding to $\mathrm{DMU}_{k}$ is considered as the optimal weights of $\mathrm{DMU}_{k}$ in order to obtain positive weights (see Remark 2 ). In the second stage, using a one-step process of AHP (Step 3 in Section 3), the vector weights of the pairwise comparison matrix, generated 
TABLE 2: Example 1: DMUs' data (extracted from [[22], p. 689]).

\begin{tabular}{|c|c|c|c|c|c|c|}
\hline \multirow{2}{*}{ Branch } & \multicolumn{3}{|c|}{ Input } & \multicolumn{3}{|c|}{ Output } \\
\hline & Staff & Computer terminals & Space $\mathrm{m}^{2}$ & Deposits & Loans & Charge \\
\hline 1 & 0.9503 & 0.70 & 0.1550 & 0.1900 & 0.5214 & 0.2926 \\
\hline 2 & 0.7962 & 0.60 & 1.0000 & 0.2266 & 0.6274 & 0.4624 \\
\hline 3 & 0.7982 & 0.75 & 0.5125 & 0.2283 & 0.9703 & 0.2606 \\
\hline 4 & 0.8651 & 0.55 & 0.2100 & 0.1927 & 0.6324 & 1.0000 \\
\hline 5 & 0.8151 & 0.85 & 0.2675 & 0.2333 & 0.7221 & 0.2463 \\
\hline 6 & 0.8416 & 0.65 & 0.5000 & 0.2069 & 0.6025 & 0.5689 \\
\hline 7 & 0.7189 & 0.60 & 0.3500 & 0.1824 & 0.9000 & 0.7158 \\
\hline 8 & 0.7853 & 0.75 & 0.1200 & 0.1250 & 0.2340 & 0.2977 \\
\hline 9 & 0.4756 & 0.60 & 0.1350 & 0.0801 & 0.3643 & 0.2439 \\
\hline 10 & 0.6782 & 0.55 & 0.5100 & 0.0818 & 0.1835 & 0.0486 \\
\hline 11 & 0.7112 & 1.00 & 0.3050 & 0.2117 & 0.3179 & 0.4031 \\
\hline 12 & 0.8113 & 0.65 & 0.2550 & 0.1227 & 0.9225 & 0.6279 \\
\hline 13 & 0.6586 & 0.85 & 0.3400 & 0.1755 & 0.6452 & 0.2605 \\
\hline 14 & 0.9763 & 0.80 & 0.5400 & 0.1443 & 0.5143 & 0.2433 \\
\hline 15 & 0.6845 & 0.95 & 0.4500 & 1.0000 & 0.2617 & 0.0982 \\
\hline 16 & 0.6127 & 0.90 & 0.5250 & 0.1151 & 0.4021 & 0.4641 \\
\hline 17 & 1.0000 & 0.60 & 0.2050 & 0.0900 & 1.0000 & 0.1614 \\
\hline 18 & 0.6337 & 0.65 & 0.2350 & 0.0591 & 0.3492 & 0.0678 \\
\hline 19 & 0.3715 & 0.70 & 0.2375 & 0.0385 & 0.1898 & 0.1112 \\
\hline 20 & 0.5827 & 0.55 & 0.5000 & 0.1101 & 0.6145 & 0.7643 \\
\hline
\end{tabular}

in the first stage, are calculated. The DEA-efficient DMUs are ranked based on these weights. The pairwise comparison matrix $\mathbf{A}$ is generated by $\theta_{i j}$ as follows:

$$
\begin{array}{r}
\mathbf{A}=\left[a_{i j}\right] \quad \text { in which, } \\
a_{i j}=\frac{\theta_{i i}+\theta_{i j}}{\theta_{j j}+\theta_{j i}}, \quad i, j=1, \ldots, n, \quad\left(\theta_{i i}=\theta_{i i}^{*}\right) .
\end{array}
$$

Moreover, since the pairwise comparison matrices are constructed from objective data in our case, we are not concerned about the consistency of $\mathbf{A}$.

Remark 3. It is evident that $a_{i i}=1, a_{i j}=1 / a_{j i}, i, j=1, \ldots, n$.

It should be noted that since we intend to rank CCRefficient DMUs, it is enough to compute the values of $a_{i j}$ for each pair of CCR-efficient DMUs $\mathrm{DMU}_{i}$ and $\mathrm{DMU}_{j}$. After determining the pairwise comparison matrix A, AHP technique is applied for ranking CCR-efficient DMUs. In this paper we use the eigenvector method (EVM) for determining eigenvalue and eigenvector of the pairwise comparison matrix A.

\section{Numerical Examples}

In this section, two numerical examples are examined to illustrate the proposed method. Comparisons with other existing procedures will also be made. In Example 2 we compare the proposed method with two other ranking methods which are based on AHP.
Example 1. We evaluated with our method the data of 20 branch banks of Iran. This data was previously analyzed by Amirteimoori and Kordrostami [22] and is listed in Table 2. Running the DEA model (4) will result in seven efficient units as $1,4,7,12,15,17$, and 20 . Using the abovementioned method the optimal weights corresponding to CCR-efficient $\mathrm{DMU}_{j}, j=1,4,7,12,15,17,20$, are chosen. The results are summarized in Table 3 . The cross efficiency and pairwise comparison matrices of seven CCR-efficient DMUs are shown in Tables 4 and 5, respectively. For this pairwise comparison matrix, $\lambda_{\max }=7.0111825, \mathrm{CI}=$ 0.00186375 , and $\mathrm{CR}=0.00141<1$. So, pairwise comparison matrix is consistent enough. The corresponding eigenvector (weights) is shown in the last column of Table 5. Table 6 shows a comparison of our proposal and some other ranking approaches. All these approaches are implemented in inputoriented version under the condition of CRS. As reported in Table 6, $\mathrm{DMU}_{4}$ is the most efficient one in our method. According to the results, the rankings of DMUs by the four methods are almost similar; in particular, the results of our method are more similar to the method [21].

Example 2. Consider a performance assessment problem investigated by Sinuany-Stern et al. [17], which includes eight DMUs to be evaluated in light of two inputs and two outputs. The data set is provided in Table 7, together with the CCRefficiencies of the eight DMUs, where the CCR efficiencies evaluate DMUs $A, B$, and $D$ to be all DEA efficient and they need to be further differentiated.

Table 8 shows the results obtained using the ranking methods of Alirezaee and Sani [20] and Sinuany-Stern et al. 


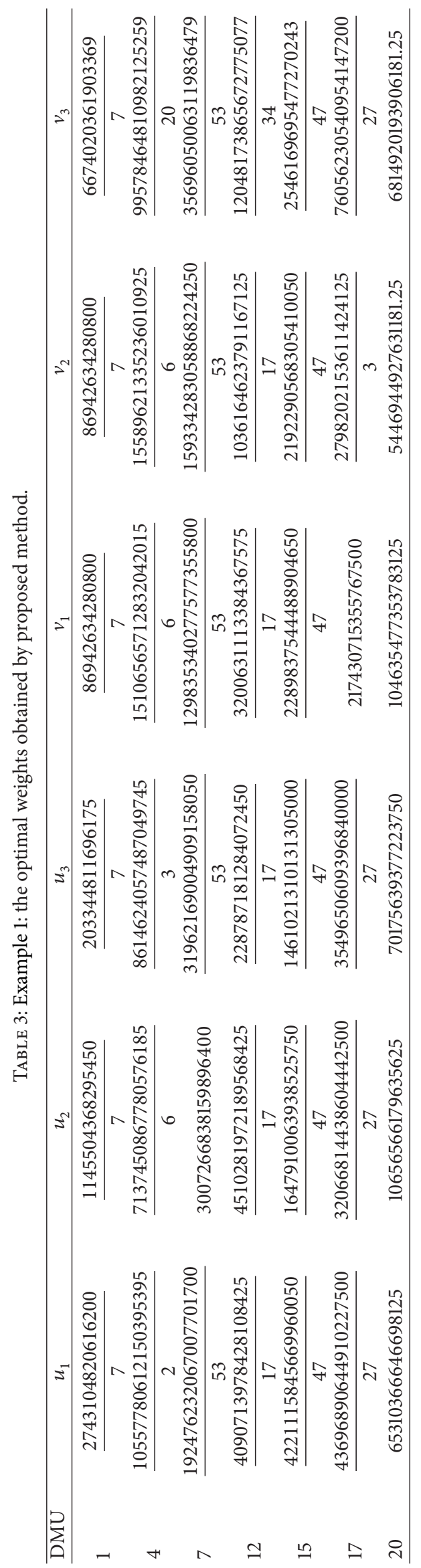


TABLE 4: Example 1: cross efficiency matrix for CCR-efficient DMUs.

\begin{tabular}{lccccccc}
\hline DMU & \multicolumn{7}{c}{ Target DMU } \\
& 1 & 4 & 7 & 12 & 15 & 17 & 0.74467050 \\
\hline 1 & 1 & 0.49504029 & 0.53660363 & 0.67987789 & 0.50878889 & 0.36909990 \\
4 & 0.95525399 & 1 & 0.81873718 & 0.84047040 & 0.89121676 & 0.92400072 & 0.94263179 \\
7 & 0.68426795 & 0.80156597 & 1 & 0.98769702 & 0.85624403 & 0.85682199 & 0.88697995 \\
12 & 0.83162917 & 0.71092883 & 0.87483547 & 1 & 0.75165252 & 0.91722504 & 0.68657179 \\
15 & 0.97375065 & 0.91292479 & 0.92595846 & 0.89933688 & 1 & 0.84347305 & 0.93897325 \\
17 & 0.94554521 & 0.41786480 & 0.78137007 & 0.97194231 & 0.54846678 & 1 & 0.25490089 \\
20 & 0.33804338 & 0.65282037 & 0.79256331 & 0.62361928 & 0.68029207 & 0.49238820 \\
\hline
\end{tabular}

TABLE 5: Example 1: pairwise comparison matrices of seven CCR-efficient DMUs.

\begin{tabular}{|c|c|c|c|c|c|c|c|c|}
\hline & $\mathrm{DMU}_{1}$ & $\mathrm{DMU}_{4}$ & $\mathrm{DMU}_{7}$ & $\mathrm{DMU}_{12}$ & $\mathrm{DMU}_{15}$ & $\mathrm{DMU}_{17}$ & $\mathrm{DMU}_{20}$ & Weight \\
\hline $\mathrm{DMU}_{1}$ & 1 & 0.7646271 & 0.9123273 & 0.9171495 & 0.7644273 & 0.8967514 & 1.0232103 & 0.33493 \\
\hline $\mathrm{DMU}_{4}$ & 1.3078269 & 1 & 1.0095312 & 1.0757141 & 0.9886519 & 1.3569705 & 1.1753435 & 0.42144 \\
\hline $\mathrm{DMU}_{7}$ & 1.0960978 & 0.9905587 & 1 & 1.0601981 & 0.9638027 & 1.0423561 & 1.0526712 & 0.38601 \\
\hline $\mathrm{DMU}_{12}$ & 1.0903347 & 0.9296149 & 0.9432199 & 1 & 0.9222442 & 0.9722520 & 1.0387729 & 0.36912 \\
\hline $\mathrm{DMU}_{15}$ & 1.3081688 & 1.0114783 & 1.0375567 & 1.0843114 & 1 & 1.1905150 & 1.1539501 & 0.41546 \\
\hline $\mathrm{DMU}_{17}$ & 1.115136 & 0.7369356 & 0.9593650 & 1.0285398 & 0.8399725 & 1 & 0.8408676 & 0.34737 \\
\hline $\mathrm{DMU}_{20}$ & 0.9773161 & 0.8508150 & 0.9499641 & 0.9626742 & 0.8665885 & 1.1892478 & 1 & 0.36284 \\
\hline
\end{tabular}

TABLE 6: Example 1: results for comparing.

\begin{tabular}{lcccccccc}
\hline \multirow{2}{*}{$\mathrm{DMU}_{k}$} & \multicolumn{2}{c}{ Proposed method } & \multicolumn{2}{c}{ Model (6) } & \multicolumn{2}{c}{ Model (6) (AP) } & \multicolumn{2}{c}{ Model (9) $l_{1}$-norm } \\
& Weight & Rank & $\Omega_{b}$ & Rank & $\theta^{*}$ & Rank & \multicolumn{1}{c}{$\Gamma(X, Y)$} & 0.0156 \\
\hline 1 & 0.33493 & 7 & 0.675 & 6 & 1.1009 & 7 & 2 \\
4 & 0.42144 & 1 & 0.708 & 2 & 1.9336 & 2 & 0.4802 \\
7 & 0.38601 & 3 & 0.698 & 3 & 1.1737 & 5 & 0.1915 & 3 \\
12 & 0.36912 & 4 & 0.677 & 5 & 1.1095 & 6 & 0.0589 & 6 \\
15 & 0.41546 & 2 & 0.790 & 1 & 4.9139 & 1 & 0.7965 \\
17 & 0.34737 & 6 & 0.677 & 5 & 1.3484 & 3 & 0.1760 \\
20 & 0.36284 & 5 & 0.680 & 4 & 1.1849 & 4 & 0.1077 \\
\hline
\end{tabular}

TABLE 7: Example 2: DMUs' data (extracted from [17]).

\begin{tabular}{lccccc}
\hline DMU & \multicolumn{2}{c}{ Input } & \multicolumn{2}{c}{ Output } & CCR efficiency \\
\hline A & 20 & 12 & 60 & 36 & 1 \\
B & 10 & 15 & 30 & 45 & 1 \\
C & 15 & 12 & 30 & 36 & 0.999 \\
D & 5 & 70 & 15 & 80 & 1 \\
E & 3 & 9 & 3 & 9 & 0.510 \\
F & 9 & 18 & 1 & 18 & 0.402 \\
G & 63 & 19 & 8 & 19 & 0.330 \\
H & 22 & 73 & 1 & 3 & 0.022 \\
\hline
\end{tabular}

[17] and the proposed method. By our method DMU $A$ has the best performance. In contrast, DMU $A$ has the worst performance by Alirezaee's method. In view of inputs and outputs of the efficient DMUs, it seems that our method gives more reasonable result than Alirezaee's method.

\section{Conclusion}

In this paper we propose a two-stage method for ranking all extreme and nonextreme efficient DMUs based on cross efficiency and AHP technique. In the first stage, cross efficiency score of each DEA-efficient DMU is calculated. In general, the optimal input-output weights obtained by classical DEA are not unique; therefore, the cross efficiency scores depending on these weights are also not unique. To remove this problem we first obtain all alternative optimal solutions of DEA model (5) and then the arithmetic mean of them is considered as a secondary goal. In the second stage, using a one-step process of AHP, the DEA-efficient DMUs are ranked. It seems that the proposed method gives more reasonable results, because 
TABLE 8: Example 2: the results of ranking methods.

\begin{tabular}{cccccc}
\hline & Sinuany's method & \multicolumn{2}{c}{ Alirezaee's method } & \multicolumn{2}{c}{ Proposed method } \\
\hline B & 0.20994 & B & 0.1993 & A & 0.591675 \\
A & 0.153001 & D & 0.1929 & B & 0.582900 \\
D & 0.14140 & A & 0.1883 & D & 0.556908 \\
\hline
\end{tabular}

we consider all alternative weights corresponding to DEAefficient DMUs. Also, our method can be extended to interval cross efficiency and interval AHP. We suggest as future works a deeper analysis in this subject. Finally, in this paper we rank CCR-efficient DMUs; in a similar way one can also rank BCCefficient DMUs.

\section{Conflict of Interests}

The author declares that there is no conflict of interests regarding the publication of this paper.

\section{References}

[1] A. Charnes, W. W. Cooper, and E. Rhodes, "Measuring the efficiency of decision making units," European Journal of Operational Research, vol. 2, no. 6, pp. 429-444, 1978.

[2] R. D. Banker, A. Charnes, and W. W. Cooper, "Some mode ls for estimating technical and scale inefficiencies in data envelopment analysis," Management Science, vol. 30, no. 9, pp. 1078-1092, 1984.

[3] D. D. Wu, "BiLevel programming data envelopment analysis with constrained resource," European Journal of Operational Research, vol. 207, no. 2, pp. 856-864, 2010.

[4] D. D. Wu, "Performance evaluation: an integrated method using data envelopment analysis and fuzzy preference relations," European Journal of Operational Research, vol. 194, no. 1, pp. 227-235, 2009.

[5] D. Wu and C.-G. Lee, "Stochastic DEA with ordinal data applied to a multi-attribute pricing problem," European Journal of Operational Research, vol. 207, no. 3, pp. 1679-1688, 2010.

[6] D. Wu, O. Baron, and O. Berman, "Bargaining in competing supply chains with uncertainty," European Journal of Operational Research, vol. 197, no. 2, pp. 548-556, 2009.

[7] J.-X. Chen and M. Deng, "A cross-dependence based ranking system for efficient and inefficient units in DEA," Expert Systems with Applications, vol. 38, no. 8, pp. 9648-9655, 2011.

[8] G. R. Jahanshahloo, H. V. Junior, F. H. Lotfi, and D. Akbarian, "A new DEA ranking system based on changing the reference set," European Journal of Operational Research, vol. 181, no. 1, pp. 331-337, 2007.

[9] S. Li, G. R. Jahanshahloo, and M. Khodabakhshi, "A superefficiency model for ranking efficient units in data envelopment analysis," Applied Mathematics and Computation, vol. 184, no. 2, pp. 638-648, 2007.

[10] F. H. Lotfi, A. A. Noora, G. R. Jahanshahloo, and M. Reshadi, "One DEA ranking method based on applying aggregate units," Expert Systems with Applications, vol. 38, no. 10, pp. 1346813471, 2011.

[11] S. Mehrabian, M. R. Alirezaee, and G. R. Jahanshahloo, "A complete efficiency ranking of decision making units in data envelopment analysis," Computational Optimization and Applications, vol. 14, no. 2, pp. 261-266, 1999.
[12] N. Adler, L. Friedman, and Z. Sinuany-Stern, "Review of ranking methods in the data envelopment analysis context," European Journal of Operational Research, vol. 140, no. 2, pp. 249-265, 2002.

[13] P. Andersen and N. C. Petersen, "A procedure for ranking efficient units in data envelopment analysis," Management Science, vol. 39, no. 10, pp. 1261-1264, 1993.

[14] Y.-M. Wang, Y. Luo, and L. Liang, "Ranking decision making units by imposing a minimum weight restriction in the data envelopment analysis," Journal of Computational and Applied Mathematics, vol. 223, no. 1, pp. 469-484, 2009.

[15] L. M. Seiford and J. Zhu, "Infeasibility of super-efficiency data envelopment analysis models," INFOR Journal, vol. 37, no. 2, pp. 174-187, 1999.

[16] T. L. Saaty, The Analytic Hierarchy Process: Planning, Priority Setting and Resource Allocation, McGraw-Hill, New York, NY, USA, 1980.

[17] Z. Sinuany-Stern, A. Mehrez, and Y. Hadad, "An AHP/DEA methodology for ranking decision making units," International Transactions in Operational Research, vol. 7, no. 2, pp. 109-124, 2000.

[18] J. Jablonsky, "Using analytic hierarchy process as a tool for ranking of efficient units in dea models," in Proceedings of the International Symposium on the Analytic Hierarchy Process, 2011.

[19] J. Jablonsky, "Measuring the efficiency of production units by AHP models," Mathematical and Computer Modelling, vol. 46, no. 7-8, pp. 1091-1098, 2007.

[20] M.-R. Alirezaee and M. R. Sani, "New analytical hierarchical process/data envelopment analysis methodology for ranking decision-making units," International Transactions in Operational Research, vol. 18, no. 5, pp. 533-544, 2011.

[21] G. R. Jahanshahloo, F. Hosseinzadeh Lotfi, N. Shoja, G. Tohidi, and S. Razavian, "Ranking using $l_{1}$-norm in data envelopment analysis," Applied Mathematics and Computation, vol. 153, no. 1, pp. 215-224, 2004.

[22] A. Amirteimoori and S. Kordrostami, "Efficient surfaces and an efficiency index in DEA: a constant returns to scale," Applied Mathematics and Computation, vol. 163, no. 2, pp. 683-691, 2005.

[23] F. Zahedi, "The analytic hierarchy process-a survey of $t$ he method and its applications," Interfaces, vol. 16, no. 4, pp. 96108, 1986.

[24] R. Ramanathan, "Data envelopment analysis for weight derivation and aggregation in the analytic hierarchy process," Computers \& Operations Research, vol. 33, no. 5, pp. 1289-1307, 2006.

[25] G. Crawford and C. Williams, "A note on the analysis of subjective judgment matrices," Journal of Mathematical Psychology, vol. 29, no. 4, pp. 387-405, 1985.

[26] F. A. Lootsma, Multi-Criteria Decision Analysis via Ratio and Difference Judgement, vol. 29 of Applied Optimization, Kluwer Academic, Dordrecht, The Netherlands, 1999.

[27] N. K. M. Bryson and A. Joseph, "Generating consensus priority point vectors: a logarithmic goal programming approach," 
Computers and Operations Research, vol. 26, no. 6, pp. 637-643, 1999.

[28] Y.-M. Wang, C. Parkan, and Y. Luo, "A linear programming method for generating the most favorable weights from a pairwise comparison matrix," Computers \& Operations Research, vol. 35, no. 12, pp. 3918-3930, 2008.

[29] Y.-M. Wang, K.-S. Chin, and G. K. K. Poon, "A data envelopment analysis method with assurance region for weight generation in the analytic hierarchy process," Decision Support Systems, vol. 45, no. 4, pp. 913-921, 2008.

[30] T. R. Sexton, R. H. Silkman, and A. J. Hogan, "Data envelopment analysis: critique and extensions," in Measuring Efficiency: An Assessment of Data Envelopment Analysis, R. H. Silkman, Ed., pp. 73-105, Jossey-Bass, San Francisco, Calif, USA, 1986.

[31] Y.-M. Wang and K.-S. Chin, "Some alternative models for DEA cross-efficiency evaluation," International Journal of Production Economics, vol. 128, no. 1, pp. 332-338, 2010.

[32] Y.-M. Wang, K.-S. Chin, and Y. Luo, "Cross-efficiency evaluation based on ideal and anti-ideal decision making units," Expert Systems with Applications, vol. 38, no. 8, pp. 10312-10319, 2011.

[33] H. H. Örkcü and H. Bal, "Goal programming approaches for data envelopment analysis cross efficiency evaluation," Applied Mathematics and Computation, vol. 218, no. 2, pp. 346-356, 2011.

[34] J. Doyle and R. Green, "Efficiency and cross-efficiency in DEA: derivations, meanings and uses," Journal of the Operational Research Society, vol. 45, no. 5, pp. 567-578, 1994.

[35] J. R. Doyle and R. Green, "Cross-evaluation in DEA: improving discrimination among DMUs," INFOR: Information Systems and Operational Research, vol. 33, no. 3, pp. 205-222, 1995.

[36] G. R. Jahanshahloo, F. Hosseinzadeh Lotfi, and D. Akbarian, "Finding weak defining hyperplanes of PPS of the BCC model," Applied Mathematical Modelling, vol. 34, no. 11, pp. 3321-3332, 2010. 


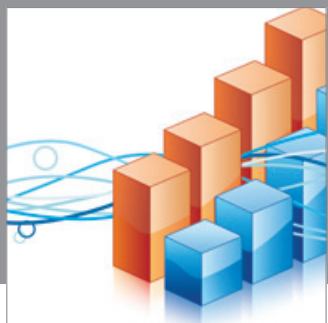

Advances in

Operations Research

mansans

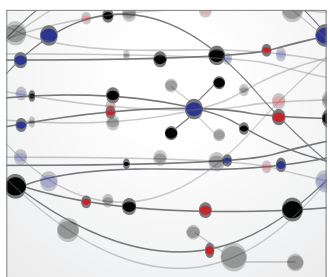

The Scientific World Journal
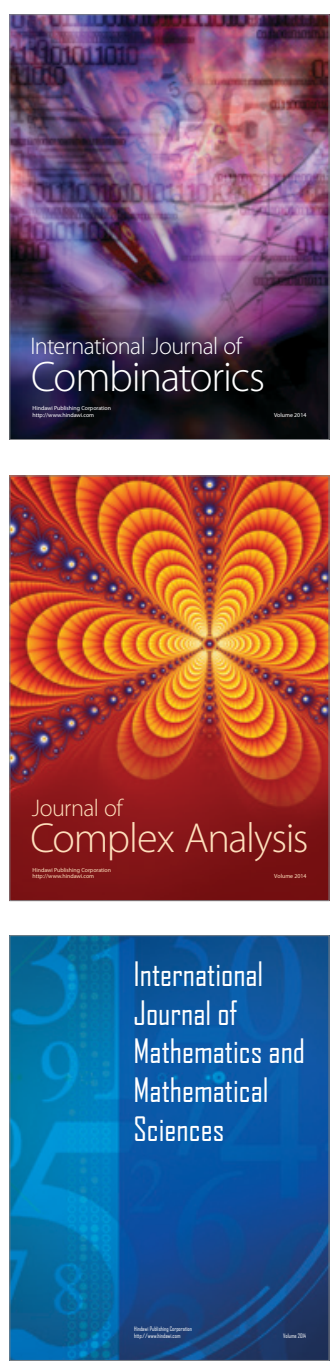
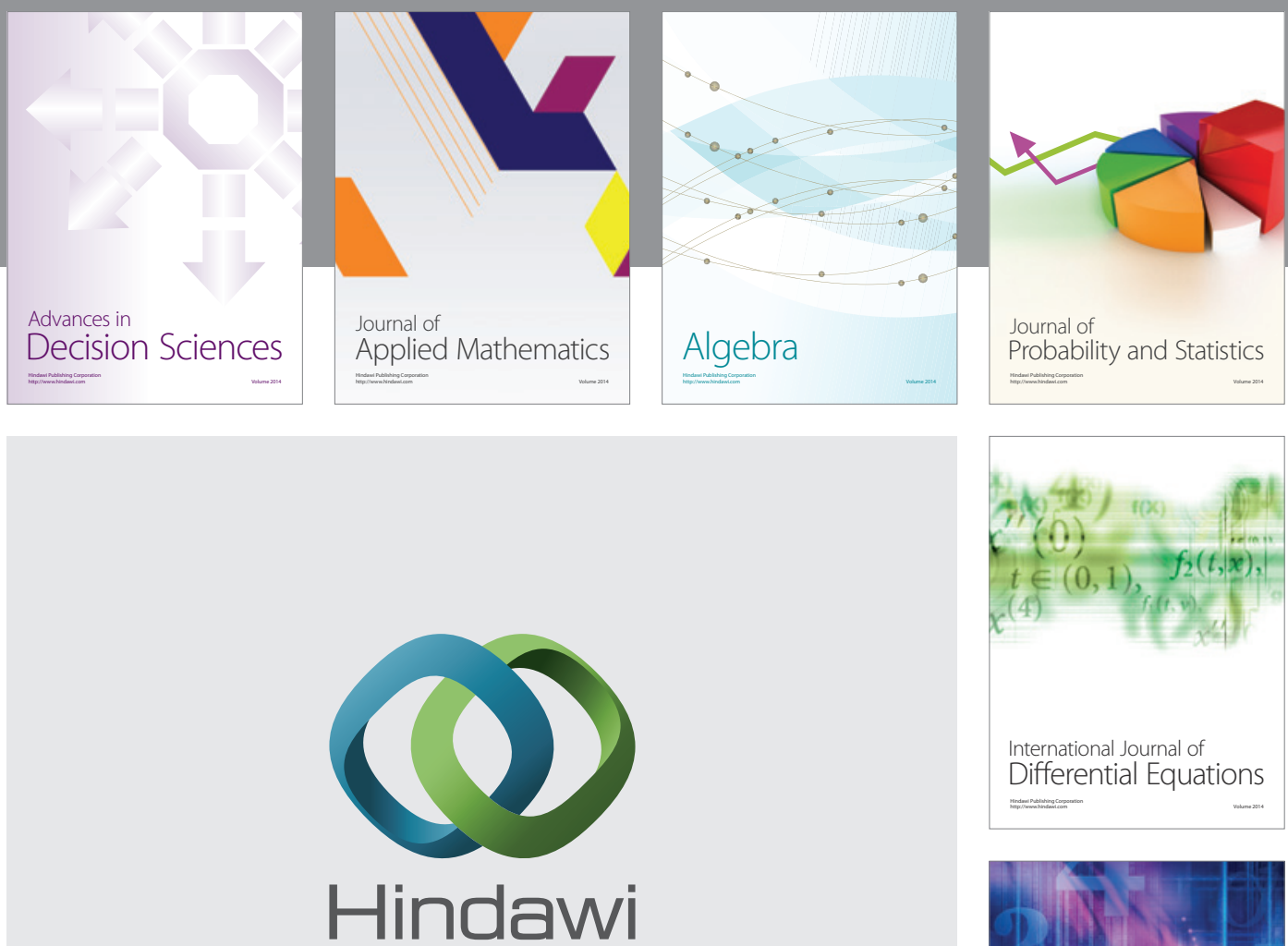

Submit your manuscripts at http://www.hindawi.com
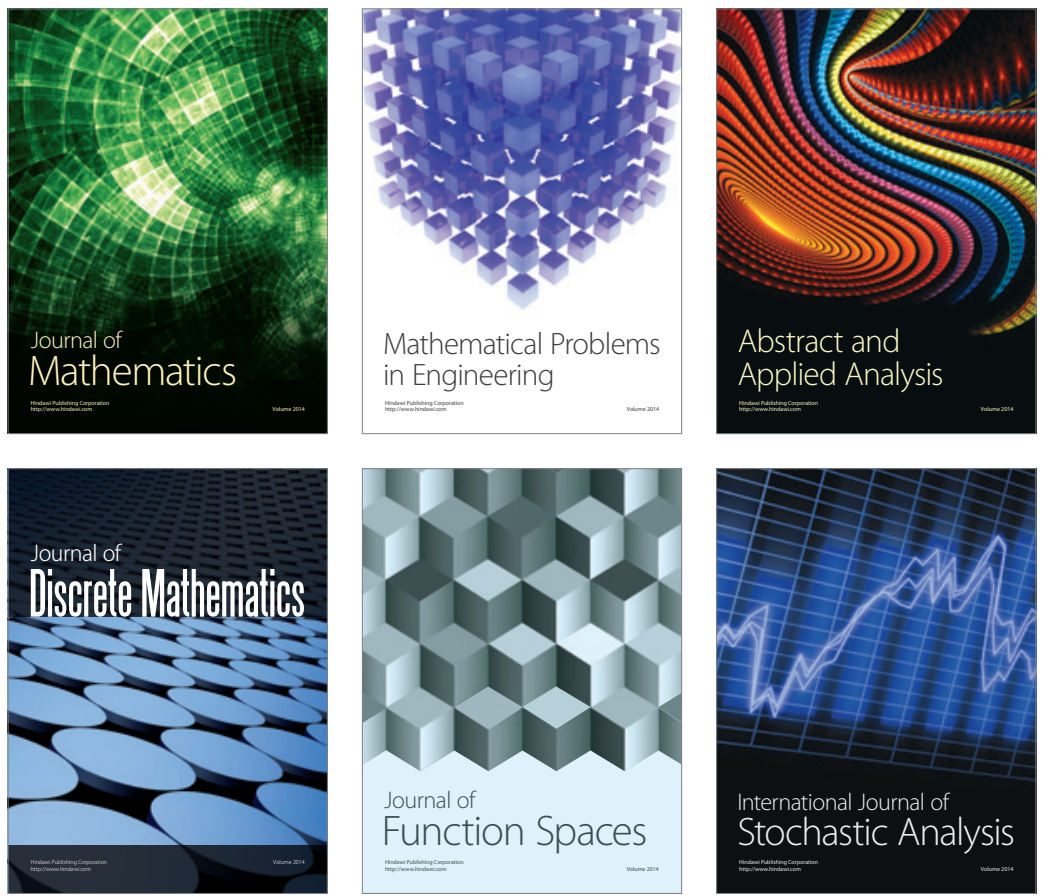

Journal of

Function Spaces

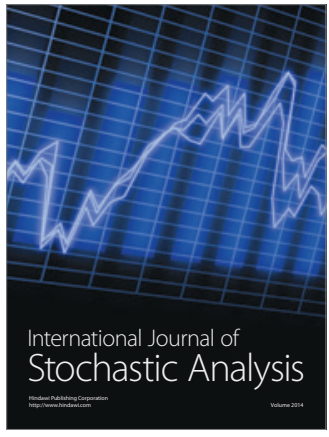

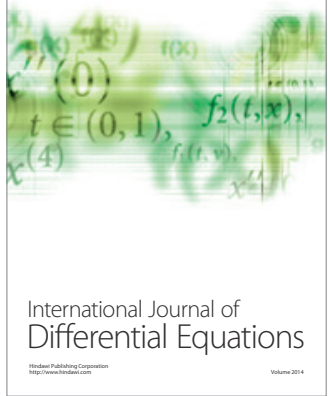
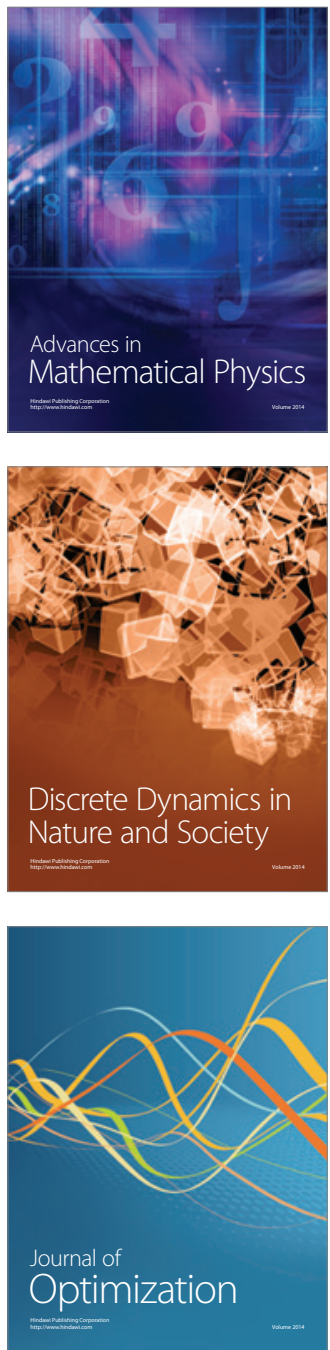